Rev. Elev. Méd. vét. Pays trop., 1972, 25 (4) : 497-506

\title{
Étude des propriétés biologiques du virus de l'encéphalomyélite porcine malgache
}

\author{
par J. RAMISSE (*), H. SERRES (*), P. RASOLOFOMANANA (*), \\ E. RAKOTONDRAMARY (*) et R. RANDRIAMAMPIANINA (*)
}

\begin{abstract}
RESUME
Toutes les techniques mises en cuvre n'ont pas permis de différencier le virus de l'encéphalomyélite porcine malgache de deux souches européennes du virus de Teschen, exception faite de la difficulté de l'infection buccale du porc et de l'absence de multiplication intestinale, avec les souches locales.

L'immunofluorescence donne des résultats en accord avec ceux de l'histochimie: replication cytoplasmique du virus. L'immunodiffusion est positive avec le virus de culture cellulaire. La séro-neutralisation montre l'antigénicité croisée entre les souches locales et européennes.

Le virus présente une étroite spécificité d'hôte et d'effet cytopathogène. Seules les cellules rénales de porc y sont sensibles. Sur ce système cellulaire, il produit des plages de dimensions variables.

La multiplication de ce virus est partiellement inhibée en culture cellulaire par le virus de Newcastle.

Les passages du virus en série sur cellules rénales de porc atténuent son pouvoir pathogène, tout en lui conservant un pouvoir immunisant.
\end{abstract}

Dans un précédent travail publié dans cette même revue (9), nous avons relaté les résultats de nos études sur les propriétés physico-chimiques du virus de l'encéphalomyélite porcine malgache, en les comparant avec celles des souches européennes de la maladie de Teschen.

Nous relatons maintenant, ci-après, l'étude que nous avons effectuée sur les propriétés biologiques du virus local, en faisant également, dans quelques cas, le parallèle avec les souches européennes.

Ces propriétés biologiques sont présentées en fonction des techniques utilisées, techniques dont certaines ont déjà été appliquées soit à des entérovirus humains ou animaux, soit plus particulièrement parfois au virus de Teschen.

(*) I.E.M.V.T., Laboratoire Central de l'Elevage. B.P. $n^{\circ} 862$, Tananarive, République Malgache.

(**) Adresse actuelle: I.E.M.V.T., 10, rue Pierre Curie, 94700 Maisons Alfort, France.

\section{A. Immunofluorescence}

Elle a été appliquée aux entérovirus par BROWN (3). De tous les procédés mis en cuvre, un seul nous a permis de caractériser correctement le virus intracellulaire : c'est l'utilisation, pour la préparation du conjugué, de sérum de porc convalescent. Pour la préparation du conjugué et la coloration des cultures cellulaires infectées, nous avons adopté la même technique que celle appliquée au virus de Newcastle (RAMISSE et Collab.) (7). L'examen a été fait sur fond noir.

Les préparations cellulaires infectées et témoins ont été colorées avec le conjugué antiTeschen soit pur, soit dilué au 1/10 et contrecolorées au bleu de méthylène. La photo 1 représente une préparation de cellules infectées examinée à moyen grossissement. Les cellules sont lysées et agglomérées en amas nettement fluorescents. La fluorescence est plus ou moins 


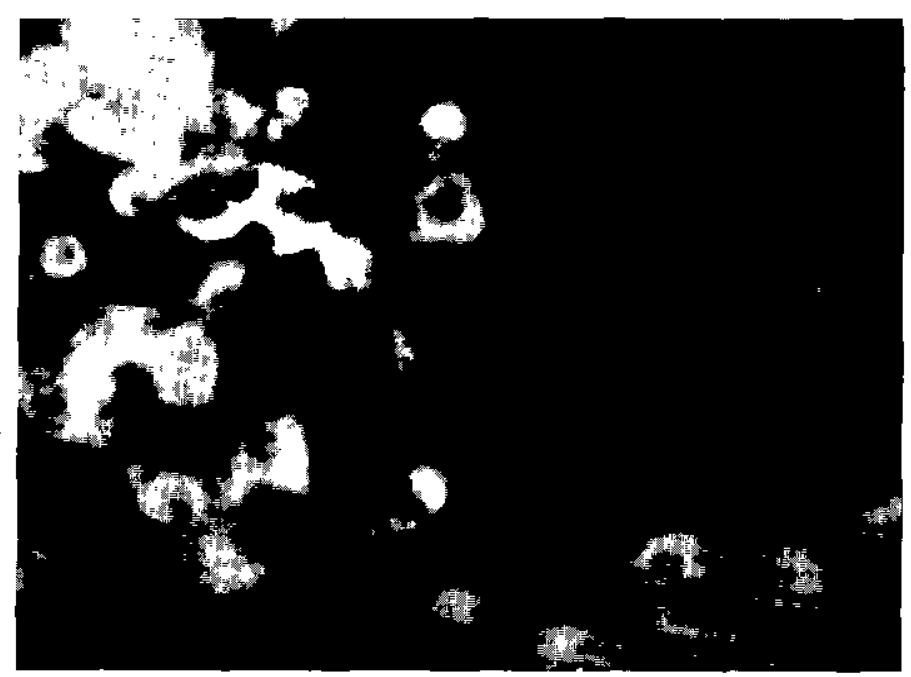

Photo 1.

intense dans le cytoplasme, mais elle est absente du noyau. Cela montre que la replication du virus est intracytoplasmique.

\section{B. Hémagglutination}

Elle a été utilisée pour les entérovirus porcins par WEBSTER (12) et MORIMOTO (6). Nous l'avons pratiquée à différentes températures, et avec les hématies (fraîches ou formolées) de porc, souris, cobaye, lapin, veau, mouton, poulet.

Quelles que soient la température de la réaction, ou l'espèce animale ayant fourni les hématies, le virus local, pas plus que le virus européen, n'ont présenté de propriétés hémagglutinantes.

\section{Immunodiffusion}

Elle a été appliquée au virus de Teschen par WITTMAN (13) puis à divers picornavirus du porc par BOULANGER et Collab., (1). Nous nous sommes servis d'antisérums préparés sur porcs ou sur moutons, et absorbés fortement avec de la poudre de rein de porc ( $1 \mathrm{~g} / \mathrm{ml}$, à 4 degrés, pendant 3 jours). Le gel de diffusion est classique : agar Noble DIFCO, tampon véronal, $\mathrm{pH} 8$ et force ionique de 0,025 . Le virus est introduit sous forme de culture cellulaire inféctée brute, ou sous forme de cerveaux virulents broyés. La diffusion est faite à 25 degrés pendant 4 jours. Ensuite, on dessèche l'agar et les lignes de précipitation sont colorées à l'amido-schwartz.
Avec les antisérums bruts non absorbés, il y a plusieurs lignes de précipitation. Ceci s'explique par l'existence d'anticorps correspondants aux composants non viraux de l'antigène d'immunisation (débris cellulaires, protéines diverses). L'adsorption des sérums avec de la poudre de tissu rénal et de l'hydrolysat de caséine fait disparaître toutes les lignes de précipitation non spécifiques.

Si l'on utilise au départ des antisérums de titre neutralisant élevé $(1 / 10.000)$, les résultats sont constants avec le virus de culture cellulaire: toutes les souches examinées donnent une ligne de précipitation, qu'il s'agisse des souches locales ou européennes. Les témoins milieu de culture et culture cellulaire non. infectée ne précipitent pas (photo 2).

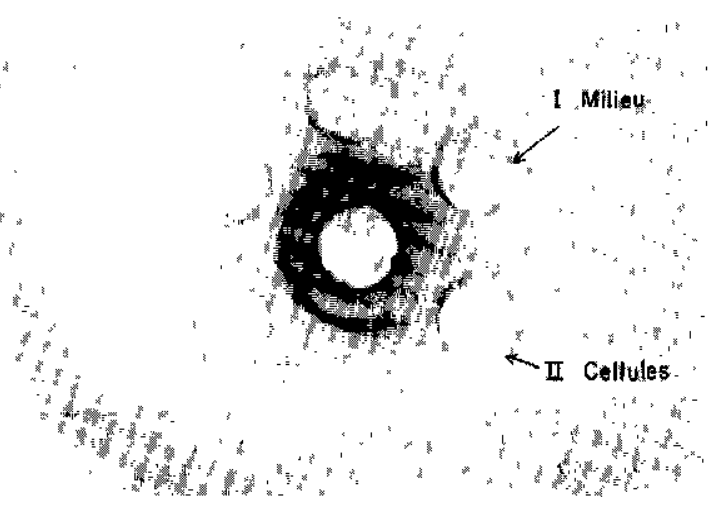

Photo 2. 
A l'inverse du virus de culture, le virus contenu dans les tissus nerveux virulents ne donne aucune ligne. Il n'est donc pas possible, dans ces conditions, de se servir de l'immunodiffusion pour le diagnostic rapide de la maladie de Teschen.

L'immunodiffusion ne permet pas de différencier les souches de Madagascar et de Tchécoslovaquie.

\section{Production de plages sur cellules rénales de porc}

La technique a été employée pour les entérovirus porcins par SINGH et Collab. (10). Nous avons utilisé soit des tubes à lamelle, soit des flacons en plastique "Falcon" de $30 \mathrm{ml}$, soit des flacons plats en verre ordinaire de $125 \mathrm{ml}$. Dans les flacons en verre ordinaire, la culture cellulaire n'est pas toujours satisfaisante.

Nous nous sommes servis de cellules de premier explant ou de premier repiquage ou de cellules de souche PK 15. Comme milieu solide, nous nous sommes arrêtés à un mélange d'agar Noble DIFCO (15 p. 1.000) et de milieu de Schwöbel sans phosphate (pH 7,8) enrichi avec 2 p. 100 de sérum de veau. La mise en évidence des plages est faite par coloration au rouge neutre à la dilution finale de $1 / 20.000$. Le rouge neutre est appliqué directement (solution au 1/5.000) ou incorporé dans une deuxième couche de milieu solidifié.

Les souches locales aussi bien que les souches européennes produisent des plages sur cellules rénales de porc en couche mono-cellulaire. Ces plages sont décelables aux plus faibles dilutions de virus $\left(10^{-2}, 10^{-3}\right)$ dès le deuxième jour. Aux dilutions plus poussées $\left(10^{-\pi}, 10^{-6}\right.$, $10^{-7}$ ), les plages n'apparaissent que vers le $4^{\mathrm{e}}$ ou $5^{\mathrm{e}}$ jour.

Le nombre de plages est beaucoup plus grand sur cellules de premier explant que sur PK 15, ce qui correspond aux titres obtenus en milieu liquide sur ces deux systèmes cellulaires.

Le diamètre des plages est très variable (de 1 à $4 \mathrm{~mm}$ ) pour une préparation virulente non purifiée.

Par cette technique nous n'avons pas davantage pu établir de différences entre les souches locales et européennes, examinées sous forme de suspensions virulentes brutes non clonées. Les photos 3 et 4 montrent l'aspect des plages obtenues en tubes à lamelles, et en flacons plats avec une souche locale et une souche européenne.

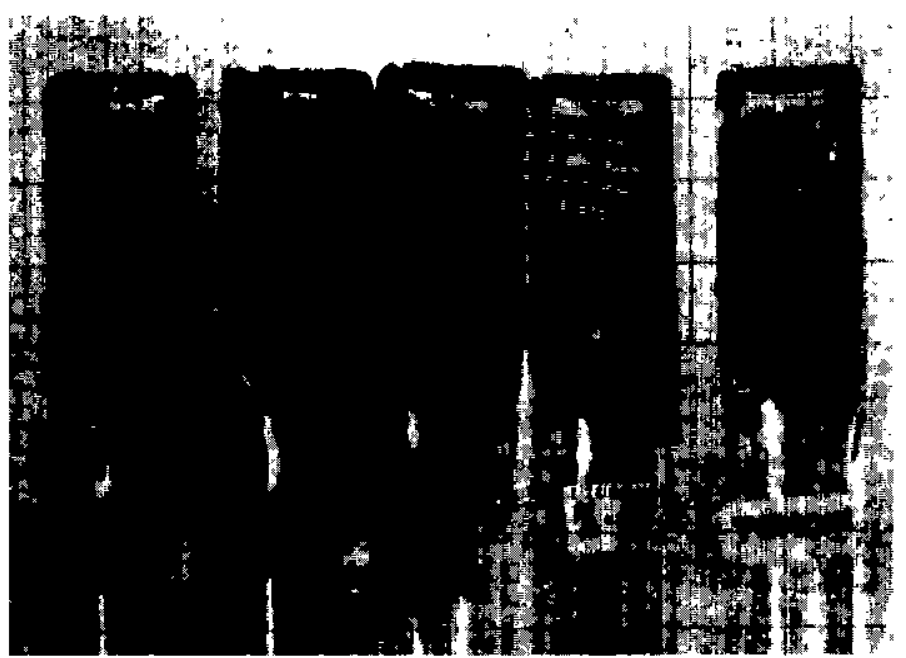

Photo 3. 


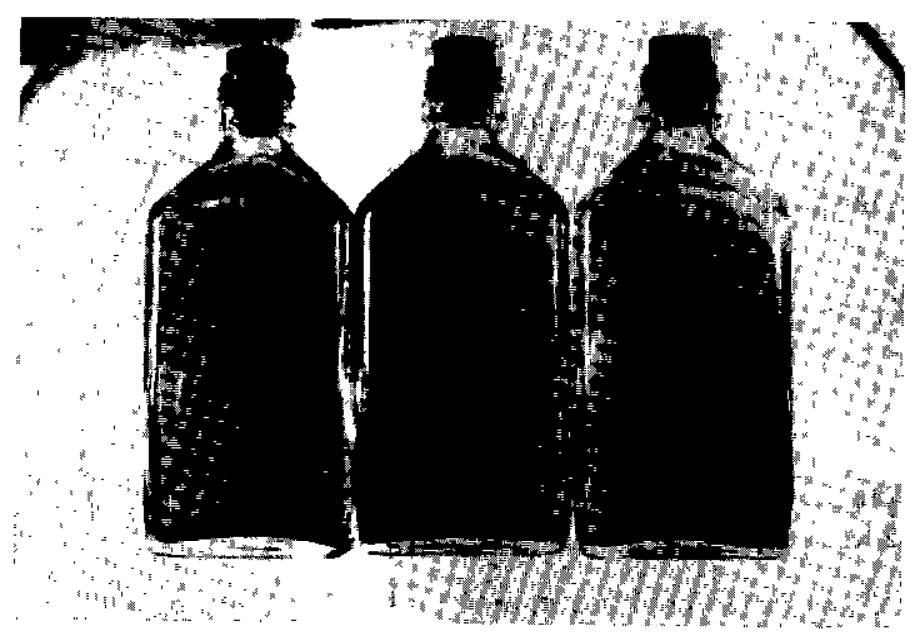

Photo 4.

\section{E. Regroupement antigénique par séro-neutralisation}

De nombreux auteurs ont utilisé la séroneutralisation spécifique du pouvoir cytopathogène, afin de classer les picornavirus du porce. L'un des travaux les plus récents et les plus complets est celui de WANG et DUNNE (11).

Nous donnons ci-après la neutralisation comparée de souches de Madagascar et de Tchécoslovaquie :
Antisérums utilisés :

Européens : anti-Konratice et anti-Tyrol.

Locaux : produit, sur moutons et sur porcs, avec des souches européennes (ZABREH envoyée par le Professeur JACOTOT, que nous remercions), ou locales (ANTSIRABE, D 388, TD 7 purifiée au Fréon).

Les virus sont employés sous forme de lysats centrifugés de cultures cellulaires infectées, titrées puis congelées.

TABLEAU N ${ }^{\circ} \mathrm{I}$

Neutralisation de diverses souches

(Diminution du tıtre cytopathogène par l'action de 3 sérums à dilution fixe)

\begin{tabular}{|c|c|c|c|c|c|c|c|c|c|c|c|c|c|c|c|c|}
\hline $\begin{array}{l}\quad \text { Virus } \\
\text { Anti- } \\
\text { Sërums }\end{array}$ & $\vec{y}$ & in & in & $\begin{array}{l}\stackrel{0}{ન} \\
\text { 帛 }\end{array}$ & 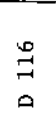 & $\begin{array}{l}\text { in } \\
\text { ñ } \\
0\end{array}$ & $\stackrel{\rho}{9}$ & $\begin{array}{l}0 \\
\infty \\
\infty \\
0\end{array}$ & $\begin{array}{l}\infty \\
\infty \\
m \\
n\end{array}$ & $\stackrel{m}{\mathfrak{w}}$ & \begin{tabular}{l}
$n$ \\
sn \\
\multirow{2}{0}{} \\
0
\end{tabular} & $\begin{array}{l} \pm \\
0 \\
0\end{array}$ & సू & $\begin{array}{l}\underset{N}{N} \\
\text { ্ָ- }\end{array}$ & 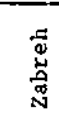 & 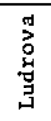 \\
\hline $\begin{array}{l}\text { Antsirabe } \\
(1 / 20.000)\end{array}$ & $10^{2}$ & $10^{2}$ & $10^{2}$ & & $10^{4}$ & $10^{3}$ & $10^{3}$ & $10^{3}$ & & $10^{4}$ & $10^{4}$ & $10^{3}$ & $10^{3}$ & $10^{2}$ & $10^{2}$ & $10^{2}$ \\
\hline $\begin{array}{l}\text { D } 388 \\
(1 / 20.000)\end{array}$ & - & - & $10^{3}$ & $10^{3}$ & $10^{3}$ & $10^{4}$ & - & - & $10^{2}$ & $10^{2}$ & - & $10^{2}$ & $10^{3}$ & $10^{3}$ & $10^{3}$ & $10^{2}$ \\
\hline $\begin{array}{l}\text { Zabreh } \\
(1 / 20.000)\end{array}$ & - & - & $10^{3}$ & $10^{3}$ & $10^{2}$ & - & - & - & $10^{2}$ & $10^{3}$ & - & $10^{2}$ & $10^{2}$ & $10^{4}$ & $10^{4}$ & $10^{4}$ \\
\hline
\end{tabular}

TABLEAU $\mathrm{N}^{\circ} \mathrm{I} T$

Neutralisations de souches européennes et malgaches par des antisĕrums européens et malgaches

\begin{tabular}{|c|c|c|c|}
\hline Virus & $\begin{array}{c}\text { Anti- } \\
\text { Sérums }\end{array}$ & $\begin{array}{c}\text { Konratice } \\
(1 / 80)\end{array}$ & $\begin{array}{c}\text { Tyrol } \\
(1 / 160)\end{array}$ \\
\hline Zabreh & $10^{3}$ & $10^{3}$ \\
\hline Ludrova & $10^{2}$ & $1 / 20.000)$ \\
\hline D 388 & $10^{2}$ & $10^{2}$ & $10^{3}$ \\
\hline D 116 & $10^{2}$ & $10^{2}$ & $10^{2}$ \\
\hline
\end{tabular}




\section{Technique :}

Les différents sérums ont été engagés dans la réaction à la dilution qui neutralise 1.000 doses cytopathogènes ZABREH. Cette dilution linite a été déterminée préalablement :

- sérum anti-Konratice : $1 / 80$,

- sérum anti-Tyrol : 1/60,

- sérum anti-A 41 (souche locale) : 1/20.000,

- sérum anti-D 388 (souche locale) : $1 / 20.000$,

- sérum anti-Zabreh (souche tchèque) : $1 / 20.000$.

Les cellules d'une même culture sont utilisées pour titrer parallèlement l'activité cytopathogène de dilutions décimales des divers virus, et de ces mêmes virus soumis à l'action des antisérums aux dilutions fixes précédemment définies.

Chaque souche est opposée à chaque sérum. L'activité de chacun de ces derniers sur chaque virus est mesurée par la différence observée dans le titre décimal limite du pouvoir cytopathogène viral, suivant que le virus est utilisé après exposition de 1 heure à $37^{\circ}$, soit tel queı, soit en présence de sérum aux dilutions définies plus haut.

Les résultats sont groupés dans les tableaux I et II. Leur examen montre une homogénéité des réactions sérologiques, qu'il s'agisse de souches européennes ou malgaches.

\section{F. Interaction avec le virus Newcastle}

BUCK et collab. (4) ont montré que certaines relations pouvaient exister entre les virus de Teschen et de Newcastle, chez le porc.

Afin de préciser la relation entre les deux virus, nous avons inoculé le virus de Newcastle à des cultures de cellules rénales de porc, et ces cultures ont été surinfectées par du virus de Teschen. La multiplication du virus de Newcastle a été démontrée par un effet cytopathogène, mais aussi par le test d'hémadsorption, tandis que le virus de Teschen a été caractérisé par l'effet cytopathogène (ECP) et par iminunofluorescence.

Les résultats sont rassemblés au tableau III.

TABLEAU $N^{\bullet}$ III

Infection successive Newcastle et Teschen sur cellules rénales de porc.

\begin{tabular}{|c|c|c|c|c|c|c|c|c|c|c|c|}
\hline $\begin{array}{l}\text { Dilution } \\
\text { Newcastle }\end{array}$ & $10^{-1}$ & $10^{-2}$ & $10^{-3}$ & $10^{-4}$ & $10^{-5}$ & $10^{-6}$ & $10^{-7}$ & $10^{-8}$ & $10^{-9}$ & $10^{-10}$ & $\mathrm{~T}$ \\
\hline $\mathrm{ECP}$ & - & - & - & + & + & + & + & - & - & - & - \\
\hline Hêmad sorption & - & - & - & + & + & + & + & - & - & - & - \\
\hline $\begin{array}{l}\text { Dilution } \\
\text { Newcastle }\end{array}$ & $10^{-1}$ & $10^{-2}$ & $10^{-3}$ & $10^{-4}$ & $10^{-5}$ & $10^{-6}$ & $10^{-7}$ & $10^{-8}$ & $10^{-9}$ & $10^{-10}$ & $\mathrm{~T}$ \\
\hline $\begin{array}{l}\text { Surinfection } \\
\text { Teschen }\end{array}$ & $10^{-4}$ & $D M I / C$ & - & Le len & $\operatorname{man} d$ & la pri & -infec & n Newc & the. & & \\
\hline ECP & - & - & - & + & + & + & + & + & + & + & - \\
\hline Hémad sorption & - & - & - & + & + & + & + & - & - & - & - \\
\hline $\begin{array}{l}\text { I. fluorescence } \\
\text { Teschen }\end{array}$ & - & - & - & - & - & - & - & + & + & + & - \\
\hline Conclusion & \multicolumn{3}{|c|}{ Pas de virus } & \multicolumn{4}{|c|}{ Newcast $1 \mathrm{e}$} & \multicolumn{3}{|c|}{ Teschen } & \\
\hline
\end{tabular}

On observe d'abord pour l'infection Newcastle une sorte de phénomène de zone. Avec les dilutions les plus faibles (jusqu'à $10^{-3}$ ), il n'y a pas d'effet cytopathogène dû au virus
Newcastle, et celui-ci ne se réplique pas intégralement sur les cellules rénales de porc ainsi que le montre le test d'hémadsorption négatif. 
Le virus de Newcastle se multiplie lorsqu'il est inoculé aux dilutions allant de $10^{-4}$ à $10^{-\tau}$.

Si l'on inocule simultanément les deux virus, le virus de Teschen plus cytopathogène se multiplie seul et lyse rapidement les cellules.

Par contre si l'on inocule le virus de Newcastle $24 \mathrm{~h}$ avant le virus de Teschen, on observe des effets variables selon les dilutions. La surinfection Teschen étant faite à une dilution unique $10^{-4}$ D.M.I., on constate :

- que, dans les tubes ayant reçu le virus de Newcastle aux plus fortes concentrations, non seulement le virus de Newcastle ne se développe pas, mais aussi qu'il n'y a pas réplication du virus de Teschen, sans doute à cause d'un phénomène d'interférence de type particulier;

- que dans les tubes où se multiplie le virus de Newcastle (dilution $10^{-4}$ à $10^{-7}$ ), il n'y a pas réplication du virus de Teschen. Ceci est montré par l'immunofluorescence. Il y aurait donc, ici, un véritable phénomène d'interférence classique entre le virus de Newcastle et le virus de Teschen;
- que le virus de Teschen se multiplie dans Ies tubes où le virus de Newcastle est absent (à partir de la dilution $10^{-8}$ ).

Ce phénomène d'interférence constaté en cultures cellulaires ne se retrouve pas, lors de l'expérimentation sur porc.

\section{G. Stabilité de l'adsorption du virus sur le gel d'alumine}

Pour évaluer la stabilité de l'adsorption du virus sur le gel d'alumine, nous avons titré le virus non inactivé restant dans le surnageant de centrifugation du mélange culture cellulaire virulente et gel d'alumine.

Le titrage a été fait après des délais de conservation variables en chambre froide.

Tout le virus présent dans le milieu de culture ne se fixe pas sur le gel d'alumine lors de la préparation du vaccin. Et même une partie de celui qui s'y fixe pendant la phase d'agitation, se libère ensuite, et se retrouve dans le milieu. L'instabilité de l'adsorption du virus sur le gel ressort des résultats des titrages rassemblés dans le tableau IV.

TABLEAU $\mathrm{N}^{\circ} \mathrm{IV}$

Titrages du virus dans la phase liquide après mélange avec le gel

\begin{tabular}{|c|c|c|c|}
\hline $\begin{array}{l}\text { Souches } \\
\text { virales }\end{array}$ & $\begin{array}{l}\text { Durée d'agitation du } \\
\text { mélange virus et ge } 1\end{array}$ & $\begin{array}{l}\text { Durée de conservation } \\
\text { en chambre froide }\end{array}$ & $\begin{array}{l}\text { Titre du virus non fixé } \\
\text { restant dans le milieu } \\
\text { (surnageant de contrifugation) }\end{array}$ \\
\hline $\begin{array}{ll}\text { TD } & 14 \\
\text { TD } & 14 \\
\text { TD } & 14 \\
\text { TD } & 14\end{array}$ & $\begin{array}{c}0 \text { (pas de ge } 1 \text { ) } \\
5 \text { minutes } \\
20 \text { minutes } \\
1 \text { heure }\end{array}$ & $\begin{array}{r}\text { titrage immédiat } \\
" 1 \\
\text { " }\end{array}$ & $\begin{array}{l}10^{8} \\
10^{5} \\
10^{5} \\
10^{5}\end{array}$ \\
\hline $\begin{array}{ll}\text { TD } & 15 \\
\text { TD } & 15 \\
\text { TD } & 15 \\
\text { TD } & 15 \\
\text { TD } & 15 \\
\text { TD } & 15\end{array}$ & $\begin{array}{c}\text { o (pas de gel) } \\
1 \text { heure } \\
1 \text { heure } \\
1 \text { heure } \\
1 \text { heure } \\
1 \text { heure }\end{array}$ & $\begin{array}{c}\text { titrage inmédiat } \\
" \\
24 \text { heures } \\
48 \text { heures } \\
5 \text { jours } \\
6 \text { jours }\end{array}$ & $\begin{array}{l}10^{B} \\
10^{4} \\
10^{2,5} \\
10^{3} \\
10^{4} \\
10^{5}\end{array}$ \\
\hline
\end{tabular}

On remarque que :

- la proportion de virus fixé dépend peu du temps d'agitation du mélange culture cellulaire et gel d'alumine;

- la proportion fixée varie selon la durée de conservation et elle semble passer par un maximum au bout de 2 à 3 jours de conservation.

\section{H. Etude de l'effet cytopathogène éventuel vis-à-vis de plasieurs systèmes cellulaires}

Dans l'espoir d'atténuer davantage les souches utilisées pour la vaccination nasale, nous avons essayé d'adapter une souche cultivée sur cellules rénales de porc à d'autres systèmes cellulaires. De plus, nous voulions vérifier la sensibilité au virus local de lignées cellulaires. 
Nous avons donc passé plusieurs fois le virus sur :

- cellules primaires: rénales de lapin et d'embryon de lapin, de cobaye, de souris, de foetus de veau, testiculaires de porc, leucocytes de porc, fibroblastes d'embryon de poulets;

- cultures mixtes: cellules rénales et testiculaires de porc, rénales de porc et de lapin. Dans ce cas, au bout de 10 à 15 passages, le virus produit (par la lyse des cellules rénales de porc) a été inoculé sur des cultures pures de cellules testiculaires de porc ou rénales de lapin, afin de contrôler s'il avait acquis un pouvoir cytopathogène pour ces cellules;

- lignées cellulaires: KB, Hela, Hep, BHK 21, PK 15, RV (rénales de veau).

Malgré la répétition des essais, nous n'avons pas pu mettre en évidence d'effet cytopathogène dû au virus Teschen (local ou européen) sur d'autres systèmes cellulaires que les cellules rénales de porc, soit primaires ou secondaires, soit en lignée continue (PK 15).

Le titre est plus élevé ( $10^{8}$ habituellement) sur cellules primaires que sur PK $15\left(10^{3}\right.$ $\left.10^{4}\right)$.

Les passages successifs sur cultures mixtes n'ont pas permis d'adapter le virus aux cellules testiculaires de porc ou rénales de lapin. Dans les cultures mixtes, seules les cellules rénales de porc étaient lysées.

\section{Inoculations expérimentales aux animaux de laboratoire}

Le virus est inoculé sous forme de suspension cérébrale ou de cultures cellulaires virulentes. Il s'agit de souches européennes ou locales récemment isolées, ou au contraire, passées de 20 à 40 fois sur cellules rénales de porc. Les voies d'inoculation et les doses sont les suivantes:

- Poulets :

intracérébrale : $0,05 \mathrm{ml}$

intranasale: 4 gouttes par narine

- Souris :

intracérébrale : $0,025 \mathrm{ml}$

intranasale: 2 gouttes par narine

- Lapereaux :

intracérébrale : $0,05 \mathrm{ml}$ intranasale: 4 gouttes par narine

- Cobayes :

intracérébrale : $0,05 \mathrm{ml}$

intranasale: 4 gouttes par narine

Les animaux inoculés sont observés pendant 1 mois au moins.

Aucun des animaux inoculés n'a présenté de symptômes particuliers pendant la période d'observation suivant l'inoculation. Par conséquent, ces animaux demeurent réfractaires au virus de l'encéphalomyélite porcine.

\section{J. Pathogénie de la maladie : infection par voie buccale}

Avec les souches malgaches fraîchement isolées, il est très difficile d'obtenir l'infection par voie buccale, comme l'a déjà signalé SERRES (9).

Nous avons confirmé qu'aucune maladie clinique n'est consécutive à l'infection de porcelets âgés de plus de 1 mois après l'administration de quantités très importantes de virus $\left(20 \mathrm{ml}\right.$ de suspension contenant $10^{6}$ unités virulentes $/ \mathrm{ml}$ par voie intracérébrale).

Par contre, la même infection se montre positive sur des porcelets âgés de 15 jours, au moment où l'immunité disparaît. Dans deux cas sur cinq, les porcelets succombent à une maladie paralytique classique, et présentent des lésions histologiques caractéristiques du système nerveux central.

Néanmoins, l'élimination fécale du virus ne peut pas être mise en évidence.

De ce point de vue, on note une différence certaine entre souches malgaches et européennes, car ces dernières permettent plus facilement l'infection par voie buccale.

\section{K. Atténuation de souches par passages sur cultures cellulaires et sélection de souches vaccinales}

Selon BOURDIN et Collab. (2), une souche locale (d'Antsirabe) passée 25 fois sur cellules rénales de porc était devenue presque inoffensive pour le porc inoculé par voie nasale, et elle avait gardé son pouvoir immunisant. Dans le but d'atténuer complètement cette souche, nous avons continué à la passer sur cellules, nous fondant sur le travail de MAYR 
qui démontrait la perte totale de virulence d'une souche passée 90 à 130 fois sur cellules. Nous avons donc passé jusqu'à 100 fois sur cellules la souche Antsirabe. A plusieurs reprises et au fur et à mesure des passages, nous avons testé sa virulence et son pouvoir vaccinant dans les conditions suivantes: inoculation nasale, observation pendant 1 mois, épreuve virulente par voie nasale ou cérébrale, autopsies systématiques des morts et des malades sacrifiés, examens histopathologiques des bulbes et moelles.

Par ailleurs, un certain nombre d'autres souches locales ou européennes ont également été passées sur cellules jusqu'au $25^{\mathrm{e}}$ passage, pour apprécier leur atténuation et leur capacité vaccinale, cela afin de sélectionner pour la vaccination nasale la souche présentant le plus faible pouvoir pathogène résiduel et la meilleure capacité vaccinale.

Enfin, deux souches ont été cultivées jusqu'au $40^{\circ}$ passage sur cellules rénales de porc à la température de $28^{\circ}$ afin de produire des souches "froides" (au sens donné par LWOFF) dont le pouvoir pathogène est habituellement réduit, ou a disparu.

Les propriétés de ces différentes souches ont été vérifiées sur porcs. D'autre part, nous avons inoculé à des porcs deux souches vivantes atténuées, par les voies intraveineuse, souscutanée et intradermique. L'épreuve de ces porcs a permis de vérifier si les porcs ainsi inoculés étaient immunisés.

TABLEAU $\mathrm{N}^{\circ} \mathrm{V}$

\begin{tabular}{|c|c|c|c|c|c|}
\hline Souche & $\begin{array}{c}\text { Passages sur } \\
\text { cellules }\end{array}$ & $\begin{array}{c}\text { Porcs } \\
\text { vaccinés }\end{array}$ & $\begin{array}{c}\text { Maladie de Teschen } \\
\text { post vaccinale }\end{array}$ & Eprouvës & Rêsistants \\
\hline \multirow{4}{*}{ Antsirabe } & 41 & 90 & 11 & 42 & 26 \\
\hline & 53 & 42 & 2 & 31 & 25 \\
\hline & 75 & 54 & 5 & 43 & 19 \\
\hline & 100 & 37 & 2 & 35 & 16 \\
\hline Zabreh & 25 & 65 & 3 & 61 & 53 \\
\hline $\begin{array}{l}\text { Antsirabe } \\
\text { cultivée } \\
\text { à } 28^{\circ}\end{array}$ & 27 & 50 & 0 & 42 & 30 \\
\hline
\end{tabular}

D'après les résultats rassemblés dans le tableau V, il n'a pas été possible jusqu'à maintenant d'obtenir une souche vivante atténuée pleinement satisfaisante, c'est-à-dire complètement dépourvue de pouvoir pathogène avec un pouvoir vaccinant élevé, et dont les propriétés seraient stables.

Pour juger de la valeur d'une souche, il faut tenir compte de la mortalité postvaccinale et du pourcentage de protection contre l'épreuve intracérébrale : l'épreuve par voie nasale quoique plus proche de l'infection naturelle ne donne pas des résultats assez réguliers, et ne tue pas chaque fois tous les témoins. C'est ainsi que les épreuves par voie nasale donnent toujours des taux de protection plus élevés pour une souche déterminée que les épreuves intracérébrales. Pour choisir une souche en vue de la vaccination nasale, dans l'état actuel des recherches, on adoptera un compromis entre le pouvoir vaccinant et le pouvoir pathogène résiduel.

Pour chaque expérience, un lot de porcelets témoins est éprouvé dans les mêmes conditions que les vaccinés. Les témoins proviennent du même lot de porcelets que les vaccinés. Nous constatons d'une expérience à l'autre des variations importantes dans la sensibilité des porcelets au virus de l'encéphalomyélite, ce qui rend difficile la comparaison entre plusieurs expériences successives.

Cependant, il est quand même possible de tirer du tableau $\mathrm{V}$ quelques conclusions :

- En premier lieu, rappelons l'inégale réceptivité des porcs vis-à-vis du virus. Cela ressort par exemple des pourcentages de mortalités postvaccinales consécutives à la vacci- 
nation avec une même souche (au même niveau de passage sur cellules).

- Aucune souche, sauf celle passée à $28^{\circ}$, n'est complètement dépourvue de pouvoir pathogène par l'inoculation nasale.

- Le pouvoir pathogène résiduel pour le porc paraît diminuer au fur et à mesure des passages sur cellules. C'est le cas de la souche A. Mais l'atténuation n'est pas très stable.

Au $25^{\text {e }}$ passage sur cellules, les 3 souches locales examinées conservent un pouvoir pathogène non négligeable. Par contre, la souche tchèque Zabreh est moins virulente.

- Le pouvoir vaccinant varie selon les souches. Aucune ne peut être considérée comme protégeant à 100 p. 100 , si l'on tient compte essentiellement des épreuves intracérébrales sur un nombre de porcs suffisamment important. Ce pouvoir vaccinant n'est pas constant et varie d'une expérience à l'autre pour une souche donnée. Peut-être cela s'explique-t-il par la variation de sensibilité des porcs.

- De même que le pouvoir pathogène résiduel paraît diminuer avec le nombre de passages sur cellules (Souche A), le pouvoir vaccinant lui aussi s'affaiblit.

Nous ne retrouvons pas, dans ce cas, de résultats comparables à ceux de MAYR et CORRENS (5).

- La souche A multipliée à $28^{\circ}$ a perdu son pouvoir pathogène mais, malheureusement, elle vaccine assez mal lorsque l'épreuve est faite par voie cérébrale.

- Deux souches locales passées 25 fois sur cellules auraient un pouvoir vaccinant acceptable (à vérifier sur un plus grand nombre de porcs), mais leur pouvoir pathogène demeure trop élevé et il n'est pas certain que l'augmentation du nombre de passages sur cellules améliore leurs propriétés (voir l'exemple de la souche A).

- La souche tchèque Zabreh, tout en ne manifestant qu'un pouvoir pathogène relativement réduit, présente des propriétés immunigènes convenables. C'est la souche actuellement la plus satisfaisante et c'est donc celle que nous utilisons pour la préparation du vaccin nasal. Il faut remarquer, à ce sujet, que la souche Zabreh provoque une immunité croisée avec les souches locales; ce qui confirme les résultats obtenus avec les séro-neutralisations croisées, et démontre la très proche parenté, sinon l'identité antigénique, entre les souches locales et la souche Zabreh.

- Le compromis optimal entre l'affaiblissement du pouvoir pathogène et le maintien du pouvoir vaccinant paraît se situer aux environs du $25^{e}$ passage sur cellules; cela rejoint l'expérimentation de BOURDIN, SERRES et Collab. (2) avec la souche A.

La conservation du pouvoir pathogène résiduel, même réduit, implique que l'emploi de ces souches atténuées soit réservé encore actuellement aux élevages immédiatement menacés, contaminés, et où il est nécessaire d'établir une immunité rapide.

\section{CONCLUSION}

Le comportement biologique du virus de l'encéphalomyélite porcine malgache confirme la conclusion tirée de l'étude de ses propriétés physico-chimiques: parenté avec les souches européennes du virus de Teschen, classification parmi les entérovirus.

\title{
SUMMARY
}

\section{Study of biological properties of malagasy porcine encephalomyelitis virus}

\begin{abstract}
No one of the technics used did permit to differentiate the virus from both european strains of Teschen disease virus except for the difficulty of the oral infection of swine and for the absence of intestinal multiplication of the local strains.

The immunofluorescent technique gives results in relation with those of the histochemistry: cytoplasmic replication of virus. The immunodiffusion is positive with the virus of cellular culture. The sero neutralization shows the cross-antigenicity between local strains and european strains of virus.
\end{abstract}


The virus presents a strict specificity of host and cytopathogenic effect. Only the renal cells of swine are sensible to it. On this cellular system, it shows plaques of variables sizes. The multiplication in cellular culture of the virus is partially inhibited by the Newcastle disease virus.

The changes of virus in series on renal cells of swine reduce its pathogenic power, but keep to the virus a protective power.

\section{RESUMEN}

\section{Estudio de algunas propiedades biologicas del virus de la encefalomielitis del cerdo malgacho}

Todas las técnicas utilizadas no permitieron diferenciar el virus de la éncefalomielitis del cerdo malgacho de dos cepas európeas del virus de Teschen excepto en lo concerniente a la dificultad de la infección bucal del cerdo y de la ausencia de multiplicación intestinal encontradas con las cepas locales.

La inmunofluorescencia da resultados marchandose bien con los de la histoquímica: replicación citoplasmica del virus. La inmunodifusión es positiva con el virus de cultivo celular. La sero-neutralización muestra la antigenicidad cruzada entre las cepas locales y európeas.

$\mathrm{El}$ virus tiene una estrecha especifidad de huesped y de efecto patógeno. Solas las células renales del cerdo son sensibles para con ello. En este sistema celular, produce playas con dimensiones variables. El virus de Newcastle inhibe parcialmente la multiplicación de dicho virus en cultivo celular.

Los pasajes del virus en serie sobre células renales del cerdo atenuan su poder patogeno, al conservar un poder inmunizante.

\section{BIBLIOGRAPHIE}

1. BOULANGER (P.), BANNISTER (G. L.) et GREIG (A.S.). The study of some viral infections of swine by means of the agar double diffusion precipitation test. Canad. J. comp. Med., 1961, 25 (5) : 113.

2. BOURDIN (P.), SERRES (H.) et RASOLOFOMANANA (P.). Encéphalomyélite porcine à Madagascar, Essais de vaccination par aérosol. Rev. Elev. Méd. vét. Pays trop., 1966, 19 (2): 119-130.

3. BROWN (G. C.). Fluorescent antibody techniques for the diagnosis of enteric infection. Arch. Ges. Virusforsch., 1963, 13: 30.

4. BUCK (G.), QUESNEL (J.J.) et RAMAMBAZAFY (H. D.). Expériences d'inoculation du porc avec le virus de la maladie de Newcastle. Ann. Inst. Pasteur, 1954, 87 (4): 450-457.

5. MAYR (A.) et CORRENS (H.). Experimentelle Untersuchungen über Lebend und Totimpf staffe aus einem modifizierten Gewebe Kultur Stamm des Teschen virus. Zentbl. Vet. Med., 1959, 6: 416.

6. MORIMOTO (T.), TOKUDA (G.), OMORI (T.), FUKUSHO (K.) et WATANABE (M.). Cytopathogenic agents isolated from the feces and the intestinal content of pigs. II. Properties of the isolates. Nat. Inst. Anim. Hlth. Quart. 1962, 2 : 66-75.

7. RAMISSE (J.), SERRES (H.) et RAKOTON-
DRAMARY (E.). Utilisation des cellules K.B. pour le diagnostic de la maladie de Newcastle et le titrage du virus. Rev. Elev. Méd. vét. Pays trop., 1969, 22 (4) : 443-452.

8. RAMISSE (J.), SERRES (H.), RASOLOFOMANANA (P.) et RAKOTONDRAMARY (E.). Etude de quelques propriétés physico-chimiques du virus de l'encéphalomyélite porcine malgache. Rev. Elev. Méd. vét. Pays trop., 1971, 24 (2) : 191-201.

9. SERRES (H.). Etude sur la pathogénie et l'épidémiologie de la paralysie contagieuse des porcs à Madagascar, Rev. Elev. Méd. vét. Pays trop., 1960,13 (4) : 245-249.

10. SINGH (K. V.), BOHL (E. H.) et BIRKELAND (J.M.). The use of the plaque technique for the study of porcine enteroviruses. Am.J. vet. Res., 1959,20 (76): 568-572.

11. WANG (J. T.) et DUNNE (H.W.). Comparison of porcine picornaviruses isolated in north America and their identification with SMEDI viruses. Am. J. vet. Res., 1969, 30 (9) : 1677-1683.

12. WEBSTER (R. G.). The isolation of orphan viruses from pigs in New Zealand. Aust. J. exp. Biol. Med. Sci., 1959, 37: 263.

13. WITTMANN (G.). Virusspezifische Präzipitation bei der Austeckende Schweinelähmung (Teschener Krankheit) mit Hilfe des Agar-Diffusionsverfahrens. $\mathrm{Zbl}$. Vet. Med., 1958, 5: 505. 